\title{
Mealtime media use and cardiometabolic risk in children
}

\author{
Joseph Jamnik', Charles Keown-Stoneman ${ }^{2,3}$, Karen M Eny ${ }^{4}$, Jonathon L Maguire 2,5,6,7,8 \\ and Catherine S Birken ${ }^{1,5,7,8, *}$ for the TARGet Kids! Collaboration $†$ \\ ${ }^{1}$ Child Health Evaluative Sciences, SickKids Research Institute, Toronto, Ontario, Canada: ${ }^{2}$ The Applied Health \\ Research Centre of the Li Ka Shing Knowledge Institute of St. Michael's Hospital, Toronto, Ontario, Canada: ${ }^{3}$ Division \\ of Biostatistics, Dalla Lana School of Public Health, University of Toronto, Toronto, Ontario, Canada: ${ }^{4}$ Nutrigenomix \\ Inc., Toronto, Ontario, Canada: ${ }^{5}$ Department of Pediatrics, Faculty of Medicine, University of Toronto, Toronto, \\ Ontario, Canada: ${ }^{6}$ Department of Pediatrics, St. Michael's Hospital, Toronto, Ontario, Canada: ${ }^{7}$ Institute of Health \\ Policy, Management and Evaluation, Dalla Lana School of Public Health, University of Toronto, Toronto, Ontario, \\ Canada: ${ }^{8}$ Department of Nutritional Sciences, Faculty of Medicine, University of Toronto, Toronto, Ontario, Canada
}

Submitted 29 May 2020: Final revision received 31 August 2020: Accepted 21 September 2020: First published online 2 December 2020

\begin{abstract}
Objectives: To examine the association between mealtime media use and non-HDL-cholesterol as well as other markers of cardiometabolic risk (CMR) in children.

Design: A repeated measures study design was used to examine the association between mealtime media use and CMR outcomes. Multivariable linear regression with generalised estimating equations was used to examine the association between mealtime media use and CMR outcomes. Analyses were stratified a priori by age groups (1-4 and 5-13 years).

Setting: The TARGet Kids! Practice-based research network in Toronto, Canada. Participants: 2117 children aged 1-13 years were included in the analysis.

Results: After adjusting for covariates, there was no evidence that total mealtime media use was associated with non-HDL-cholesterol in $1-4$ year olds $(P=0 \cdot 10)$ or 5-13 year olds $(P=0 \cdot 29)$. Each additional meal with media per week was associated with decreased HDL-cholesterol in 5-13 year olds $(-0.006 \mathrm{mmol} / \mathrm{l} ; 95 \% \mathrm{CI}$ $-0.009,-0.002 ; P=0.003)$ and $\log -\mathrm{TAG}$ in $1-4$ year olds $(\beta=-0.004 ; 95 \% \mathrm{CI}$ $-0.008,-0.00009 ; P=0.04)$. Media use during breakfast was associated with decreased HDL-cholesterol in 5-13year olds $(-0.012 \mathrm{mmol} / \mathrm{l} ; 95 \% \mathrm{CI}-0.02$, -0.004; $P=0.002)$, while media during lunch was associated with decreased logTAG $(-0.01 \mathrm{mmol} / \mathrm{l} ; 95 \% \mathrm{CI}-0.03,-0.002 ; P=0.03)$ in children aged $1-4$ years. Total mealtime media use was not associated with total cholesterol, glucose or insulin in either age group.

Conclusions: Mealtime media use may be associated with unfavourable lipid profiles through effects on HDL-cholesterol in school-aged children but likely not in preschoolers.
\end{abstract}

Keywords: Mealtime media use Cardiometabolic risk Lipids Children
Excessive exposure to electronic media, including television, computers and handheld devices, during childhood has been associated with delayed language development, aggressive behaviour, smoking and obesity ${ }^{(1-4)}$. Recently, there has been increased interest in the potentially unique effects of media exposure during mealtime and its association with the development of obesity in children. Possible mechanisms to explain the link between mealtime media use and excess body weight include eating despite the lack

${ }^{\dagger}$ A complete list of group members appears in the Acknowledgments. of hunger, reduced satiety signals while watching media and exposure to advertisements promoting energy-dense foods and poor dietary habits ${ }^{(5,6)}$. A recent systematic review and meta-analysis including twenty observational studies ( $n 84825$ ) identified a positive association between television viewing during mealtime and risk of overweight/ obesity in children ${ }^{(7)}$. While studies have focused primarily on television viewing during mealtime and its association with overweight and obesity, there is no evidence on the effects of media exposure during meals on other markers of cardiometabolic risk (CMR). 
Non-HDL-cholesterol is an important marker of CMR in children and a significant predictor of dyslipidaemia in adulthood $^{(8,9)}$. Lifestyle factors have been associated with circulating levels of non-HDL-cholesterol ${ }^{(10-12)}$, and patterns of non-HDL-cholesterol identified during early childhood have been shown to persist with age ${ }^{(13)}$. In addition to non-HDLcholesterol, other CMR markers such as blood pressure, glucose and lipids have also been shown to persist into adulthood and are associated with increased risk of developing various diseases including the metabolic syndrome, type 2 diabetes and atherosclerotic plaques ${ }^{(14,15)}$. While systematic reviews assessing the association between television viewing/screen time and markers of CMR in children, including lipids, blood pressure, glucose and insulin, have yielded inconsistent results ${ }^{(16-18)}$, no studies to date have investigated the effects of mealtime media use on these CMR markers in preschool to school-aged children. The primary objective of the present study was to examine the association between total media use during mealtime and non-HDL-cholesterol levels as well as other CMR markers in children, including total cholesterol, HDL-cholesterol, TAG, glucose and insulin. Additionally, we examined whether media use during specific meals (i.e., breakfast, lunch, dinner and snacks) was associated with non-HDL-cholesterol and other CMR markers.

\section{Methods}

\section{Study design and population}

A repeated measures study was conducted in children $\geq 1$ year of age participating in the TARGet Kids (The Applied Research Group for Kids) cohort, a primary care practice-based research network with ongoing recruitment described previously (ClinicalTrials.gov: NCT0186953) ${ }^{(19)}$. Healthy children younger than 6 years at first visit were recruited and followed during well-child visits at eleven paediatric or primary care centres in Toronto, Canada. Participants were invited to participate in annual data collection. Children with severe developmental delay, any chronic condition (with the exception of asthma) or whose families were unable to complete questionnaires in English were not included. The present study included children with recorded visits from January 2013 to July 2018 (n 6566). Children without non-HDL-cholesterol laboratory values due to lack of blood draw or assay failure ( $n$ 4141) and those without mealtime media use questionnaire responses ( $n$ 162) were excluded. Children who were $<1$ year of age for their only visit ( $n$ 144) were also excluded. Data collected prior to 2013 were not utilised as questionnaires asked only about television use during mealtime, and we were interested in all forms of electronic media use.

\section{Mealtime media use assessment}

Parents were asked to complete a detailed Nutrition and Health Questionnaire at the following well-child visits:
12 months, 18 months, 2 years and yearly thereafter. The Nutrition and Health Questionnaire administered was modified from the Canadian Community Health Survey ${ }^{(20)}$ and contained questions on electronic media use during mealtime. For both a 'typical weekday' and 'typical weekend day', parents indicated typical electronic media usage during mealtime by responding to "Which meals did your child eat in a room with a screen device on (television, computer, tablet etc.)', with Yes/No responses available for 'Breakfast', 'Lunch', 'Dinner' and 'A snack'. The primary exposure variable of interest in the present study was total mealtime media use. This variable was created by adding all 'Yes' responses for each meal or snack and calculating a weighted average per week (i.e., multiplying weekday responses by 5 and weekend response by 2). Associations with total mealtime media use are reported in terms of both increasing meals per week and per day (total mealtime media use variable divided by 7 ). Electronic media use during individual meals (i.e., breakfast, lunch, dinner and snack) was calculated in the same way using only 'Yes' responses to 'Breakfast', 'Lunch', 'Dinner' and 'A snack'. Associations with meal-specific media use are reported in terms of increasing meals per week.

\section{Outcome and covariate assessment}

Non-fasting blood samples were collected by trained paediatric phlebotomists at the paediatric or primary care centres during yearly scheduled well-child visits. While blood samples were required for all participants at the time of initial recruitment, blood samples at follow-up visits were optional. Blood samples were then transported to Mount Sinai Services Laboratory, Toronto, Ontario for analysis as described previously ${ }^{(21)}$. Lipids, including total cholesterol, HDL-cholesterol and TAG, were measured using an enzymatic colorimetric assay. Non-HDL-cholesterol was calculated by subtracting HDL-cholesterol from total cholesterol. Glucose and insulin were measured using the enzymatic reference method with hexokinase and an electrochemiluminescence immunoassay, respectively. Generally, higher total cholesterol, non-HDLcholesterol, TAG, glucose and insulin are associated with increased risk of developing various adverse health outcomes. Higher HDL-cholesterol is generally associated with a decreased risk of adverse health outcomes. Time of last meal/snack and non-water drink was recorded. Fasting time was accounted for in the current analysis, despite evidence indicating that fasting time may have little influence on serum lipid levels ${ }^{(21,22)}$. Children's height and weight were measured by trained research assistants at clinical visits using a stadiometer (SECA) and precision digital scale (SECA model 703), respectively. Length boards were used for children under 2 years old. Age- and sex-standardised BMI $z$-scores (zBMI) were calculated using the $\mathrm{WHO}$ growth standards ${ }^{(23,24)}$.

Information on relevant covariates was assessed by parent-completed questionnaire during scheduled clinic visits. Covariates were identified a priori using the published literature and included child age ${ }^{(25-31)}, \operatorname{sex}^{(25-35)}$, 
birth weight ${ }^{(32,36)}$, total screen time ${ }^{(27,34-36)}$, maternal education $^{(29-32,34,36,37)}$, maternal ethnicity ${ }^{(25,27,31,35,38)}$, family income $e^{(25,27,33,36,38)}$, parental history of cardiometabolic disease (high cholesterol, hypertension, heart disease and diabetes) ${ }^{(39-41)}$ and breast-feeding duration $^{(42)}$. Additional covariates included unstructured free play time ${ }^{(26,27,29,32,34,43)}$, total screen time ${ }^{(27,34-36)}$ and family meals ${ }^{(44)}$. Unstructured free play was assessed using parents' response to the open-ended question 'Aside from time in daycare and school, on a typical weekday, how much time does your child spend outside in unstructured free play?'. Family meals were assessed by parents' response to the open-ended question 'In a typical week, how many times does your family eat the evening meal together?'. Finally, total screen time was assessed by calculating a weighted average of typical parent-reported weekday and weekend minutes spent awake in a room with the television on, videos or DVD on, playing on the computer, playing video games or playing with handheld devices ${ }^{(45)}$. Total screen time was included as a covariate so that results would likely be independent from overall media use and specific to media use during meals.

\section{Statistical analysis}

Descriptive analyses of the primary exposure, outcomes and covariates were examined for all subjects at their first recorded visit (Table 1). For all analyses, repeated measures of exposures and outcomes measured concurrently over time were used to investigate the association between total mealtime electronic media use and outcome variables. Linear regression modelling using generalised estimating equations was used to account for within-subject correlation. Such models can accommodate subjects with available data at both single and multiple time points, and they do not require that all subjects have repeated measures. All subjects with at least one measure of total mealtime media use and non-HDL-cholesterol were included. A first-order autoregressive covariance matrix, $\operatorname{AR}(1)$, with observations ordered by subjects' age in months, was used to account for correlations among repeated measures in all analyses $^{(46)}$. The AR(1) covariance matrix accounts for correlation over time for a subject with repeated measures. Under this correlation structure, correlations decline with increasing time between visits.

In the primary analysis, the association between total mealtime electronic media use and CMR outcomes was investigated using both unadjusted and fully adjusted models. The fully adjusted model accounted for covariates that have been identified in the literature as potential confounders between mealtime media use and CMR outcomes or that have been directly associated with the outcome variables. Secondary analysis between mealtime media exposure during specific meals (breakfast, lunch, dinner and snack) and CMR outcomes was conducted using the same fully adjusted models. All analyses were stratified by $a$ priori age groups (1-4 and 5-13 years). These age groups were selected since recent position statements on media use from both the American Academy of Pediatrics and the Canadian Paediatric Society specifically pertain to children $\geq 5$ years $^{(47,48)}$. Additionally, the majority of studies investigating mealtime television use and risk of overweight/obesity have been conducted in children aged 5 years and older ${ }^{(7)}$, and associations between mealtime media use and CMR markers may differ between these age groups. Interactions between mealtime media use and age group (1-4 years and 5-13 years) on each of the outcome variables were examined in models without stratification, but $P$-values and estimates of main effects are reported from models stratified by age groups, as this was specified a priori. For identified associations in either age group with $P<0.05$, additional adjustment for zBMI was done as an exploratory analysis to determine whether the identified associations were likely independent from changes in zBMI.

In order to facilitate the inclusion of subjects with missing covariate data, multiple imputation $(m=20)$ was performed using the MICE package ${ }^{(49)}$ for all adjusted models. All covariates had missing observations $<15 \%$, with the exception of maternal BMI (17\%). Participants with zBMI values $>+5$ or $<-5$ were excluded $(n 2)$ in accordance with WHO guidelines ${ }^{(50)}$. The distributions of outcome variables were assessed, and both TAG and insulin were log-transformed in order to achieve normality. For all analyses, the $\alpha$-error was set at 0.05 and statistical tests were two-sided. Statistical analysis was conducted using R version $3.5 .1^{(51)}$.

\section{Results}

A total of 2119 children $\geq 1$ year of age had at least one TARGet Kids! visit between 2013 and 2018 with complete data on electronic media use during mealtime and blood lipids. After excluding zBMI outliers ( $n$ 2), the remaining 2117 subjects were included in the final analysis. Of the 2117 subjects with at least one recorded visit, $27 \%$ ( $n$ 585) had repeated exposure and outcome data measured concurrently from two visits, and $10 \%$ ( $n$ 209) had repeated measures from three or more visits, resulting in a total of 2911 observations. There were a total of 1619 (56\%) observations in the 1-4 years age group and 1292 ( $44 \%$ ) observations in the 5-13 years group. Baseline subject characteristics for all children included in the final analysis are shown in Table 1 . Average total mealtime media use was $5.91 \pm 7.17$ meals/week among all children included in the present study at first visit. Participants had an average age of approximately 51 months and $54 \%$ of children were male. The majority of mothers were of European descent (64\%) and had a college/university degree or higher (91\%). 
Table 1 Baseline subject characteristics

\begin{tabular}{|c|c|c|}
\hline Variable & Subjects $(n)$ & Mean \pm SD or $n(\%)$ \\
\hline \multicolumn{3}{|l|}{ Participant characteristics } \\
\hline Age (months) & 2117 & $51 \cdot 35 \pm 31 \cdot 68$ \\
\hline Age groups & 2117 & \\
\hline $1-4$ years & & $1282(61)$ \\
\hline $5-13$ years & & $835(29)$ \\
\hline Sex & 2117 & \\
\hline Male & & $1138(54)$ \\
\hline Female & & $979(46)$ \\
\hline Maternal ethnicity & 1853 & \\
\hline European & & $1181(64)$ \\
\hline East/Southeast Asian & & $188(10)$ \\
\hline South Asian & & $193(10)$ \\
\hline Other & & $291(16)$ \\
\hline Maternal education & 2089 & \\
\hline High school, apprenticeship/trades certificate or no degree & & $187(9)$ \\
\hline College/university & & $1902(91)$ \\
\hline Self-reported household income & 2061 & \\
\hline$<\$ 30000$ & & $110(5)$ \\
\hline$\$ 30000-\$ 79999$ & & $374(18)$ \\
\hline$\$ 80000-\$ 149999$ & & $650(32)$ \\
\hline$\geq \$ 150000$ & & $927(45)$ \\
\hline $\mathrm{zBMI}(\mathrm{SD})$ & 2108 & $0.15 \pm 1.09$ \\
\hline Birth weight (kg) & 1881 & $3.25 \pm 0.67$ \\
\hline Average screen time $(\mathrm{min} / \mathrm{d})$ & 1991 & $86 \cdot 85 \pm 76 \cdot 11$ \\
\hline Average weekday free play $(\mathrm{min} / \mathrm{d})$ & 1988 & $50 \cdot 56 \pm 53 \cdot 17$ \\
\hline Maternal BMI & 1691 & $25.15 \pm 4.98$ \\
\hline Parental cardiometabolic disease & 1854 & \\
\hline Positive history & & $458(25)$ \\
\hline Negative history & & $1396(75)$ \\
\hline Family meals (evening meals with family/week) & 2098 & $5.30 \pm 1.93$ \\
\hline Fasting time $(\mathrm{h})$ & 2037 & $2.04 \pm 1.51$ \\
\hline \multicolumn{3}{|l|}{ Exposure variables } \\
\hline Total mealtime media use (meals/week) & 2117 & $5.91 \pm 7.17$ \\
\hline \multicolumn{3}{|l|}{ Specific meal media use (meals/week) } \\
\hline Breakfast & 2117 & $1.63 \pm 2.73$ \\
\hline Lunch & 2117 & $0.74 \pm 1.93$ \\
\hline Dinner & 2117 & $1.20 \pm 2.48$ \\
\hline Snack & 2117 & $2 \cdot 34 \pm 3 \cdot 11$ \\
\hline \multicolumn{3}{|l|}{ Outcome variables } \\
\hline Non-HDL-cholesterol (mmo/l) & 2117 & $2 \cdot 67 \pm 0.70$ \\
\hline Total cholesterol $(\mathrm{mmol} / \mathrm{l})$ & 2117 & $4.05 \pm 0.73$ \\
\hline HDL-cholesterol (mmol/l) & 2117 & $1.38 \pm 0.36$ \\
\hline $\mathrm{TAG}(\mathrm{mmol} / \mathrm{l})$ & 2117 & $1.17 \pm 0.66$ \\
\hline Glucose $(\mathrm{mmol} / \mathrm{l})$ & 2117 & $4.60 \pm 0.68$ \\
\hline Insulin $(\mathrm{mmol} / \mathrm{l})$ & 2098 & $82.75 \pm 70.00$ \\
\hline
\end{tabular}

Results of both unadjusted and fully adjusted models examining the association between total mealtime media use and CMR outcomes are shown in Table 2. Total mealtime media use was not associated with non-HDLcholesterol in children $1-4$ or 5-13 years old in both unadjusted ( $1-4$ years, $P=0.42 ; 5-13$ years, $P=0 \cdot 15$ ) and adjusted models (1-4 years, $P=0 \cdot 10$; 5-13 years, $P=0 \cdot 29)$. In children aged $1-4$ years, there was an inverse association between total mealtime media use and $\log$-TAG in both unadjusted $(P=0.003)$ and fully adjusted models $(P=0.04)$. In the adjusted model, each increase of one meal with media per day was associated with a decrease in $\log$-TAG $(\beta=-0.03 ; 95 \%$ CI -0.05 , -0.0008). This is approximately equivalent to a $3 \%$ decrease in TAG levels. The association between total mealtime media use per day and log-TAG years remained significant after additional adjustment for zBMI ( $\beta=-0.03$; $95 \%$ CI $-0.05,-0.0003 ; P=0.048)$. In children aged 5-13 years, total mealtime media use was inversely associated with HDL-cholesterol in both unadjusted $(P=0.03)$ and adjusted models $(P=0.003)$. In the adjusted model, each increase of one meal with media per day was associated with a decrease in HDL-cholesterol by $-0.04 \mathrm{mmol} / 1$ (95\% CI -0.06, -0.01). After additional adjustment for zBMI, the association between total mealtime media use per day and HDL-cholesterol remained significant $(\beta=-0.04 ; 95 \%$ CI $-0.06,-0 \cdot 01 ; P=0.004)$.

Results of the secondary analysis examining the association between media use during specific meals and non-HDL as well as other CMR markers were varied (shown in Table 3). There was no evidence for an association between 
Table 2 Linear generalised estimating equations regression for the association between total mealtime media use per week and cardiometabolic outcomes stratified by age

\begin{tabular}{|c|c|c|c|c|c|c|c|c|}
\hline & \multicolumn{4}{|c|}{ Unadjusted } & \multicolumn{4}{|c|}{ Adjusted $^{*}$} \\
\hline & Estimate & $95 \% \mathrm{Cl}$ & $P$ & $P$-int† & Estimate & $95 \% \mathrm{Cl}$ & $P$ & $P$-int† \\
\hline \multicolumn{9}{|c|}{ Non-HDL-cholesterol (mmol/l) } \\
\hline Age $1-4$ years & -0.002 & $-0.006,0.003$ & 0.43 & \multirow[t]{2}{*}{$0 \cdot 10$} & -0.004 & $-0.01,0.0008$ & $0 \cdot 10$ & \multirow[t]{2}{*}{0.06} \\
\hline Age $5-13$ years & 0.006 & $-0.002,0.014$ & 0.15 & & 0.004 & $-0.004,0.013$ & 0.29 & \\
\hline \multicolumn{9}{|c|}{ Total cholesterol $(\mathrm{mmol} / \mathrm{l})$} \\
\hline Age $1-4$ years & 0.0002 & $-0.005,0.005$ & 0.95 & \multirow[t]{2}{*}{0.68} & -0.004 & $-0.010,0.002$ & 0.17 & \multirow[t]{2}{*}{0.50} \\
\hline Age $5-13$ years & 0.002 & $-0.006,0.01$ & 0.62 & & -0.001 & $-0.010,0.007$ & 0.78 & \\
\hline \multicolumn{9}{|c|}{ HDL-cholesterol (mmol/l) } \\
\hline Age $1-4$ years & 0.002 & $-0.0003,0.004$ & 0.09 & \multirow[t]{2}{*}{0.005} & 0.0006 & $-0.002,0.003$ & 0.64 & \multirow[t]{2}{*}{0.009} \\
\hline Age $5-13$ years & -0.004 & $-0.007,-0.0004$ & 0.03 & & -0.006 & $-0.009,-0.002$ & 0.003 & \\
\hline \multicolumn{9}{|l|}{ Log-TAG (mmol/l) } \\
\hline Age $1-4$ years & -0.004 & $-0.008,-0.002$ & 0.003 & \multirow[t]{2}{*}{0.007} & -0.004 & $-0.008,-0.00009$ & 0.04 & \multirow[t]{2}{*}{0.02} \\
\hline Age $5-13$ years & 0.003 & $-0.002,0.008$ & $0 \cdot 17$ & & 0.003 & $-0.003,0.009$ & 0.29 & \\
\hline \multicolumn{9}{|l|}{ Glucose $(\mathrm{mmol} / \mathrm{l})$} \\
\hline Age $1-4$ years & -0.004 & $-0.008,0.001$ & $0 \cdot 12$ & \multirow[t]{2}{*}{0.59} & -0.001 & $-0.007,0.004$ & 0.64 & \multirow[t]{2}{*}{0.26} \\
\hline Age $5-13$ years & -0.006 & $-0.01,0.0004$ & 0.07 & & -0.005 & $-0.012,0.001$ & 0.12 & \\
\hline \multicolumn{9}{|l|}{ Log insulin (mmol/l) } \\
\hline Ăge $1-4$ years & 0.003 & $-0.003,0.008$ & 0.36 & \multirow[t]{2}{*}{0.96} & 0.003 & $-0.003,0.010$ & 0.31 & \multirow[t]{2}{*}{$0 \cdot 70$} \\
\hline Age $5-13$ years & 0.003 & $-0.005,0.01$ & 0.45 & & 0.0009 & $-0.0069,0.0086$ & 0.83 & \\
\hline
\end{tabular}

*Adjusted for child age, child sex, birth weight, fasting time, unstructured free play, total screen time, maternal education, maternal ethnicity, family income, parental history of cardiometabolic-related disease, breast-feeding duration and family meals.

$\dagger P$-values for age $\times$ total mealtime media use interactions estimated from unstratified models.

media use during any specific meal and non-HDLcholesterol in children aged $1-4$ or 5-13 years $(P>0.05)$. In children aged $1-4$ years, consuming an additional lunch with media per week was associated with decreased logTAG $(\beta=-0.01 ; 95 \% \mathrm{CI}-0.03,-0.002 ; P=0.03)$. In children aged $5-13$ years, consuming an additional breakfast with media per week was associated with decreased HDLcholesterol ( $\beta=-0.012 ; 95 \% \mathrm{CI}-0.02,-0.004 ; P=0.002)$, dinner with media was associated with increased log insulin $(\beta=0.02 ; 95 \%$ CI $0.0007,0.04 ; P=0.04)$ and snacks with media were associated with decreased glucose $(\beta=-0.02$; $95 \%$ CI $-0.03,-0.003 ; P=0.02$ ).

\section{Discussion}

The current study provides some insight into the effects of mealtime media use on CMR markers independent of body weight. Our results suggest that total mealtime media use is likely not associated with circulating levels of non-HDL-cholesterol in pre-school (1-4 years) or school-aged children (5-13 years). In school-aged children, total mealtime media use was inversely associated with HDL-cholesterol, and this association was largely driven by media usage during breakfast. In pre-school-aged children, total mealtime media use was inversely associated with TAG, and there was evidence of an association between media use during lunch and decreased TAG in this age group.

Both the American Academy of Pediatrics and Canadian Paediatric Society recently released policy statements outlining the risks of weight gain with excessive media use in school-aged children and adolescents ${ }^{(47,48)}$. The Canadian Paediatric Society also specifically recommends that screen time be limited during family routines such as meals in pre-school-aged children ${ }^{(52)}$. In a US population of schoolaged children, up to approximately $25 \%$ of energetic intake was shown to be consumed while watching television. In our study population, children consumed an average of nearly six meals ( $21 \%$ of total meals/snacks) with media per week. This may be of concern given both the positive association between mealtime media use and excess body weight ${ }^{(7)}$ and the high prevalence of obesity ${ }^{(53)}$. Furthermore, it is estimated that almost $40 \%$ of children in Canada have abnormal values for at least one cardiovascular risk factor, including BMI, blood pressure, lipids and blood glucose ${ }^{(54)}$. Such unfavourable CMR profiles have been shown to track into adulthood and lead to an increased risk of developing metabolic syndrome, atherosclerosis and type 2 diabetes ${ }^{(14,15)}$.

Exposure to media during mealtime has several potentially unique effects which may make it an especially important risk factor in the development of increased CMR. Media consumption may act as a cue to stimulate eating in the absence of hunger ${ }^{(5,6)}$. Furthermore, media use during mealtime is thought to extend meal duration and ultimately increase energetic intake through reduced satiety signals ${ }^{(6,55)}$. Additionally, exposure to food advertisements on television encouraging the consumption of energy-dense foods during mealtime may promote poor dietary habits ${ }^{(5,56,57)}$. These factors likely all contribute to reported associations between mealtime media use and poor overall diet quality. Indeed, a recent systematic review identified associations between mealtime media use and 
Public Health Nutrition

Table 3 Linear generalised estimating equations regression for the association between media use during specific meals per week and cardiometabolic outcomes stratified by age*

\begin{tabular}{|c|c|c|c|c|c|c|c|c|c|c|c|c|c|c|c|c|}
\hline & \multicolumn{4}{|c|}{ Breakfast } & \multicolumn{4}{|c|}{ Lunch } & \multicolumn{4}{|c|}{ Dinner } & \multicolumn{4}{|c|}{ Snack } \\
\hline & $\begin{array}{l}\text { Adjusted } \\
\text { estimate }\end{array}$ & $95 \% \mathrm{Cl}$ & $P$ & $P$-int $\dagger$ & $\begin{array}{l}\text { Adjusted } \\
\text { estimate }\end{array}$ & $95 \% \mathrm{Cl}$ & $P$ & $P$-int $\dagger$ & $\begin{array}{l}\text { Adjusted } \\
\text { estimate }\end{array}$ & $95 \% \mathrm{Cl}$ & $P$ & $P$-int $\dagger$ & $\begin{array}{l}\text { Adjusted } \\
\text { estimate }\end{array}$ & $95 \% \mathrm{Cl}$ & $P$ & $P$-int \\
\hline \multicolumn{17}{|c|}{ Non-HDL-cholesterol (mmol//) } \\
\hline $\begin{array}{c}\text { Age 1-4 } \\
\text { years }\end{array}$ & -0.008 & $-0.022,0.005$ & 0.22 & 0.14 & -0.005 & $-0.02,0.01$ & 0.59 & 0.09 & -0.01 & $-0.03,0.002$ & $0 \cdot 10$ & 0.19 & -0.005 & $-0.017,0.008$ & 0.47 & 0.15 \\
\hline $\begin{array}{l}\text { Age } 5-13 \\
\text { years }\end{array}$ & 0.008 & $-0.008,0.024$ & 0.34 & & 0.03 & $-0.01,0.07$ & 0.16 & & 0.002 & $-0.016,0.019$ & 0.86 & & 0.004 & $-0.010,0.017$ & 0.60 & \\
\hline \multicolumn{17}{|c|}{ Total cholesterol $(\mathrm{mmol} / \mathrm{l})$} \\
\hline $\begin{array}{c}\text { Age 1-4 } \\
\text { years }\end{array}$ & -0.009 & $-0.023,0.005$ & 0.21 & 0.66 & 0.0006 & $-0.0177,0.0190$ & 0.94 & 0.28 & -0.01 & $-0.03,0.003$ & 0.10 & 0.59 & -0.003 & $-0.017,0.010$ & 0.65 & 0.56 \\
\hline $\begin{array}{l}\text { Age } 5-13 \\
\text { years }\end{array}$ & -0.004 & $-0.020,0.012$ & 0.60 & & 0.02 & $-0.02,0.06$ & 0.28 & & -0.006 & $-0.024,0.012$ & 0.51 & & -0.002 & $-0.017,0.013$ & 0.76 & \\
\hline \multicolumn{17}{|c|}{ HDL-cholesterol (mmol/l) } \\
\hline $\begin{array}{c}\text { Age 1-4 } \\
\text { years }\end{array}$ & -0.0007 & $-0.007,0.006$ & 0.84 & 0.03 & 0.006 & $-0.003,0.014$ & 0.20 & 0.09 & -0.0004 & $-0.0071,0.0063$ & 0.90 & 0.13 & 0.002 & $-0.005,0.008$ & 0.62 & 0.10 \\
\hline $\begin{array}{l}\text { Age } 5-13 \\
\text { years }\end{array}$ & -0.012 & $-0.020,-0.004$ & 0.002 & & -0.007 & $-0.021,0.007$ & 0.34 & & -0.008 & $-0.017,0.002$ & 0.11 & & -0.006 & $-0.013,0.001$ & 0.10 & \\
\hline \multicolumn{17}{|c|}{ Log-TAG (mmol/l) } \\
\hline $\begin{array}{c}\text { Age } 1-4 \\
\text { years }\end{array}$ & -0.004 & $-0.014,0.005$ & 0.35 & 0.04 & -0.01 & $-0.03,-0.002$ & 0.03 & 0.29 & -0.01 & $-0.02,0.0004$ & 0.06 & 0.39 & -0.002 & $-0.012,0.007$ & 0.61 & 0.03 \\
\hline $\begin{array}{c}\text { Age } 5-13 \\
\text { years }\end{array}$ & 0.010 & $-0.002,0.021$ & 0.12 & & -0.0006 & $-0.0258,0.0245$ & 0.96 & & -0.005 & $-0.019,0.010$ & 0.05 & & 0.006 & $-0.003,0.015$ & 0.19 & \\
\hline \multicolumn{17}{|c|}{ Glucose (mmol/l) } \\
\hline $\begin{array}{c}\text { Age 1-4 } \\
\text { years }\end{array}$ & -0.0002 & $-0.0131,0.0127$ & 0.98 & 0.93 & 0.004 & $-0.011,0.019$ & 0.60 & 0.25 & -0.0007 & $-0.0151,0.0137$ & 0.92 & 0.63 & -0.008 & $-0.021,0.005$ & 0.21 & 0.40 \\
\hline $\begin{array}{c}\text { Age } 5-13 \\
\text { years }\end{array}$ & 0.002 & $-0.013,0.017$ & 0.80 & & -0.01 & $-0.04,0.01$ & 0.33 & & -0.005 & $-0.025,0.014$ & 0.60 & & -0.02 & $-0.03,-0.003$ & 0.02 & \\
\hline \multicolumn{17}{|c|}{ Log insulin (mmol/l) } \\
\hline $\begin{array}{c}\text { Age } 1-4 \\
\text { years }\end{array}$ & 0.008 & $-0.007,0.024$ & 0.29 & 0.24 & -0.0003 & $-0.0213,0.0206$ & 0.98 & 0.50 & 0.003 & $-0.014,0.021$ & 0.70 & 0.24 & 0.008 & $-0.007,0.023$ & 0.31 & 0.57 \\
\hline $\begin{array}{c}\text { Age } 5-13 \\
\text { years }\end{array}$ & -0.004 & $-0.022,0.012$ & 0.56 & & -0.01 & $-0 \cdot 05,0.02$ & 0.44 & & 0.02 & $0.0007,0.04$ & 0.04 & & -0.0007 & $-0.0161,0.0147$ & 0.93 & \\
\hline
\end{tabular}

*Analyses adjusted for child age, child sex, birth weight, fasting time, unstructured free play, total screen time, maternal education, maternal ethnicity, family income, parental history of cardiometabolic-related disease, breast-feeding duration and family meals.

$\dagger P$-values for age $\times$ media use during specific meals per week interactions estimated from unstratified models. 
lower scores on dietary quality indices. Specifically, watching television during mealtime was associated with decreased intake of fruits and vegetables, as well as an increased intake of fat- and sugar-containing foods including sugar-sweetened beverages ${ }^{(58)}$. Such dietary patterns have been shown to be associated with unfavourable CMR risk profiles ${ }^{(59)}$, suggesting that changes in diet quality associated with mealtime media may mediate the association with adverse CMR profiles in children.

We observed evidence of an inverse association between total mealtime media use and levels of HDL-cholesterol in children aged 5-13 years. This suggests that increased media use during mealtime may be associated with less favourable lipid profiles in school-aged children. Evidence of an inverse association between total mealtime media use and HDLcholesterol remained after additional adjustment for zBMI, suggesting that the effects of mealtime media use on lipid profiles may be independent from effects on $\mathrm{zBMI}^{(7)}$. Understanding which specific meals are driving observed associations is important because it has the potential to inform future interventions and it gives parents a practical target to focus on. When examining specific meals, evidence of an inverse association with HDL-cholesterol was only observed for breakfast consumed with media. A crosssectional study of 409 children aged 6-9 years in Iran identified a similar association between breakfast consumption while watching television and increased waist circumference as well as fasting blood sugars, but not lipids ${ }^{(60)}$. Other studies have shown that skipping breakfast is associated with unfavourable cardiometabolic profiles ${ }^{(61)}$, including decreased HDL-cholesterol in children ${ }^{(62,63)}$. It is therefore possible that media use during breakfast may act as a marker for irregular breakfast consumption patterns in the present study, possibly explaining its inverse association with HDL-cholesterol. Further research is necessary to determine the potential clinical significance of this association between mealtime media use and HDL-cholesterol.

The use of non-television forms of media such as smartphones and tablets was included in the current study. While the use of such devices among children has increased in recent years ${ }^{(64,65)}$, it is unclear whether interacting with these devices during meals has similar effects to watching television. A randomised crossover trial found that acute energy intake was lower in children who were using a computer while eating compared with children who were watching television ${ }^{(66)}$. Other studies conducted in adults $^{(67,68)}$ also suggest that different forms of media may have varying effects on distraction from satiety signals and resulting energy intake. If the use of mobile media devices while eating results in less food consumption compared with watching television or no media at all, this could potentially explain the absence of associations identified between total mealtime media use and CMR markers in the present study. Such a phenomenon could also partially explain the unexpected inverse associations we observed between media use during snack time and glucose levels in children aged 5-13 years as well as media use during lunch and TAG in children aged 1-4 years. However, it must be noted that since our study was unable to differentiate between different types of media, no conclusions about possible differential effects of mobile media $v$. other types of media can be drawn. Further studies are necessary to determine whether mobile media use during mealtime has different effects from traditional television viewing on body weight and other CMR markers in children.

We observed some differences in the direction of associations between mealtime media use and CMR markers in our two a priori age groups. In children aged 5-13 years, total mealtime media use was inversely associated with HDLcholesterol, suggesting that increased media use during mealtime may be associated with less favourable lipid profiles. Having more dinners with media was associated with increased insulin in this age group, although there was no evidence of an overall association between total mealtime media use (i.e., across all meals) and insulin. In children aged 1-4 years, we observed an unexpected inverse association between total mealtime media use and TAG. While TAG levels may be slightly affected by fasting time ${ }^{(22)}$, it is unlikely that fasting status confounded the observed association since it was adjusted for in the final analysis. The identified inverse association in this age group may also represent a spurious finding. Alternatively, it is possible that parents of preschool-aged children in the present study utilised media during mealtime as a distraction tactic to increase food intake in picky eaters. Indeed, this motivation for television viewing during mealtime has been described by parents of 3-5-yearold children participating in a recent qualitative study ${ }^{(69)}$. This suggests that the effects of media use during mealtime could differ between pre-school and school-aged children. Further research examining the context in which mealtime media is used in children of different ages may help to better explain apparent differences in the direction of associations observed between age groups in the present study.

While our study has a number of strengths, including a large sample size of over 2000 children, the utilisation of repeated measures, the inclusion of non-television forms of media and adjustment for a number of relevant covariates, it does possess some notable limitations. Given the disproportionate representation of participants from households with relatively high income and maternal education, the results may not be generalisable to the broader Canadian population. Although the administered questionnaire included all types of media use during mealtime (i.e., television, computer, video game console and handheld devices), it does not ask about mobile media (i.e., handheld devices including tablets and mobile phones) and nonmobile media use separately. This precluded any analysis of differences between mobile and non-mobile media use during mealtime. Furthermore, parental estimates of media use during meals consumed away from home (e.g., at school) may not be accurate for school-aged children with mobile devices. Additionally, while the identified 
associations were statistically significant $(P<0.05)$, the effect sizes were relatively small. However, these small effects may be of importance if they occur chronically as cumulative exposure to lower levels of HDL-cholesterol from childhood through to adulthood has been associated with increased atherosclerosis ${ }^{(70)}$. Nevertheless, since these associations have not yet been replicated in independent cohorts, it is possible that any of the observed associations in the present study represent spurious findings. Finally, the observational nature of the study precludes the establishment of causality in any of the identified associations.

\section{Conclusion}

While there was no evidence that mealtime media use was associated with non-HDL-cholesterol, it may be associated with unfavourable lipid profiles through effects on HDL-cholesterol independent of body weight in children $\geq 5$ years. This suggests that promoting media-free meals in school-aged children may have beneficial effects on minimising CMR. Additionally, the motivation for mealtime media use among children and parents may differ between pre-school and school-aged children, which may contribute to the differing direction of associations observed in our study. Further studies which examine the context for mealtime media use may help further clarify results of the present study.

\section{Acknowledgements}

Acknowledgements: The authors thank all of the participating families for their time and involvement in TARGet Kids! and are grateful to all practitioners who are currently involved in the TARGet Kids! practice-based research network. *TARGet Kids! Collaborators - Co-Leads: Catherine S. Birken, Jonathon L. Maguire; Advisory Committee: Ronald Cohn, Eddy Lau, Andreas Laupacis, Patricia C. Parkin, Michael Salter, Peter Szatmari, Shannon Weir; Science Review and Management Committees: Laura N. Anderson, Cornelia M. Borkhoff, Charles Keown-Stoneman, Christine Kowal, Dalah Mason; Site Investigators: Murtala Abdurrahman, Barbara Anderson, Kelly Anderson, Gordon Arbess, Jillian Baker, Tony Barozzino, Sylvie Bergeron, Dimple Bhagat, Nicholas Blanchette, Gary Bloch, Joey Bonifacio, Ashna Bowry, Anne Brown, Jennifer Bugera, Caroline Calpin, Douglas Campbell, Sohail Cheema, Elaine Cheng, Brian Chisamore, Evelyn Constantin, Ellen Culbert, Karoon Danayan, Paul Das, Mary Beth Derocher, Anh Do, Michael Dorey, Kathleen Doukas, Anne Egger, Allison Farber, Amy Freedman, Sloane Freeman, Sharon Gazeley, Charlie Guiang, Dan Ha, Curtis Handford, Laura Hanson, Leah Harrington, Hailey Hatch, Teresa Hughes, Sheila Jacobson, Lukasz Jagiello, Gwen Jansz, Mona Jasuja, Paul Kadar, Tara
Kiran, Holly Knowles, Bruce Kwok, Sheila Lakhoo, Margarita Lam-Antoniades, Eddy Lau, Denis Leduc, FokHan Leung, Alan Li, Patricia Li, Jennifer Loo, Joanne Louis, Sarah Mahmoud, Jessica Malach, Roy Male, Vashti Mascoll, Aleks Meret, Elise Mok, Rosemary Moodie, Julia Morinis, Maya Nader, Katherine Nash, Sharon Naymark, James Owen, Jane Parry, Michael Peer, Kifi Pena, Marty Perlmutar, Navindra Persaud, Andrew Pinto, Michelle Porepa, Vikky Qi, Nasreen Ramji, Noor Ramji, Jesleen Rana, Danyaal Raza, Alana Rosenthal, Katherine Rouleau, Janet Saunderson, Rahul Saxena, Vanna Schiralli, Michael Sgro, Hafiz Shuja, Susan Shepherd, Barbara Smiltnieks, Cinntha Srikanthan, Carolyn Taylor, Stephen Treherne, Suzanne Turner, Fatima Uddin, Meta van den Heuvel, Joanne Vaughan, Thea Weisdorf, Sheila Wijayasinghe, Peter Wong, Anne Wormsbecker, John Yaremko, Ethel Ying, Elizabeth Young, Michael Zajdman; Research Team: Farnaz Bazeghi, Vincent Bouchard, Marivic Bustos, Charmaine Camacho, Dharma Dalwadi, Christine Koroshegyi, Tarandeep Malhi, Sharon Thadani, Julia Thompson, Laurie Thompson; Project Team: Mary Aglipay, Imaan Bayoumi, Sarah Carsley, Katherine Cost, Karen Eny, Theresa Kim, Laura Kinlin, Jessica Omand, Shelley Vanderhout, Leigh Vanderloo; Applied Health Research Centre: Christopher Allen, Bryan Boodhoo, Olivia Chan, David W.H. Dai, Judith Hall, Peter Juni, Gerald Lebovic, Karen Pope, Kevin Thorpe; Mount Sinai Services Laboratory: Rita Kandel, Michelle Rodrigues, Hilde Vandenberghe. Financial support: Funding of the TARGet Kids! research network was provided by the Canadian Institutes of Health Research (CIHR) Institute of Human Development, Child and Youth Health (grant number MOP-333560), the CIHR Institute of Nutrition, Metabolism and Diabetes, the SickKids Foundation and the St. Michael's Hospital Foundation. The funding agencies had no role in the design and conduct of the study, the collection, management, analysis and interpretation of the data, or the preparation, review and approval of the manuscript. Conflict of interest: K.M.E. is an employee of Nutrigenomix Inc. The remaining authors have no conflicts of interest to disclose. Authorship: J.J. contributed to the concept and design, carried out the analysis and interpretation of data, drafted the manuscript, as well as reviewed and revised the manuscript. C.K.S. contributed to the study design, analysis and interpretation of data, and critically revised the manuscript for important intellectual content. K.M.E. contributed to the study design, analysis and interpretation of data, and critically revised the manuscript for important intellectual content. J.L.M. and C.S.B. contributed to the concept and design, coordinated and supervised data collection, and critically revised the manuscript for important intellectual content. All authors approved the final manuscript as submitted and agree to be accountable for all aspects of the work. Ethics of buman subject participation: The current study was conducted according to the guidelines laid down in the Declaration of Helsinki and all procedures involving research study participants were 
approved by the Research Ethics Boards at both The Hospital for Sick Children and St. Michael's Hospital. Written informed consent was obtained from all parents.

\section{References}

1. Christakis DA, Gilkerson J, Richards JA et al. (2009) Audible television and decreased adult words, infant vocalizations, and conversational turns: a population-based study. Arch Pediatr Adolesc Med 163, 554-558.

2. Robertson LA, McAnally HM \& Hancox RJ (2013) Childhood and adolescent television viewing and antisocial behavior in early adulthood. Pediatrics 131, 439-446.

3. Gidwani PP, Sobol A, DeJong W et al. (2002) Television viewing and initiation of smoking among youth. Pediatrics 110, 505-508.

4. Zhang G, Wu L, Zhou Let al. (2016) Television watching and risk of childhood obesity: a meta-analysis. Eur J Public Health 26, 13-18.

5. Robinson TN, Banda JA, Hale L et al. (2017) Screen media exposure and obesity in children and adolescents. Pediatrics 140, S97-S101.

6. Robinson TN \& Matheson DM (2015) Environmental strategies for portion control in children. Appetite 88, 33-38.

7. Ghobadi S, Hassanzadeh-Rostami Z, Salehi-Marzijarani M et al. (2018) Association of eating while television viewing and overweight/obesity among children and adolescents: a systematic review and meta-analysis of observational studies. Obes Rev 19, 313-320.

8. Friedman LA, Morrison JA, Daniels SR et al. (2006) Sensitivity and specificity of pediatric lipid determinations for adult lipid status: findings from the Princeton Lipid Research Clinics Prevalence Program Follow-up Study. Pediatrics 118, 165-172.

9. Srinivasan SR, Frontini MG, Xu J et al. (2006) Utility of childhood non-high-density lipoprotein cholesterol levels in predicting adult dyslipidemia and other cardiovascular risks: the Bogalusa Heart Study. Pediatrics 118, 201-206.

10. Persaud N, Maguire JL, Lebovic G et al. (2013) Association between serum cholesterol and eating behaviours during early childhood: a cross-sectional study. CMAJ 185, E531-E536.

11. Alberty R, Albertyova D \& Ahlers I (2009) Distribution and correlations of non-high-density lipoprotein cholesterol in Roma and Caucasian children: the Slovak Lipid Community Study. Coll Antropol 33, 1015-1022.

12. Kaitosaari T, Ronnemaa T, Raitakari O et al. (2003) Effect of 7-year infancy-onset dietary intervention on serum lipoproteins and lipoprotein subclasses in healthy children in the prospective, randomized Special Turku Coronary Risk Factor Intervention Project for Children (STRIP) study. Circulation 108, 672-677.

13. Albaum JM, Carsley S, Chen Y et al. (2017) Persistent high non-high-density lipoprotein cholesterol in early childhood: a latent class growth model analysis. J Pediatr 191, 152-157.

14. Juhola J, Magnussen CG, Viikari JS et al. (2011) Tracking of serum lipid levels, blood pressure, and body mass index from childhood to adulthood: the Cardiovascular Risk in Young Finns Study. J Pediatr 159, 584-590.

15. Morrison JA, Glueck CJ, Horn PS et al. (2008) Pre-teen insulin resistance predicts weight gain, impaired fasting glucose, and type 2 diabetes at age 18-19 y: a 10-y prospective study of black and white girls. Am J Clin Nutr 88, 778-788.

16. Tremblay MS, LeBlanc AG, Kho ME et al. (2011) Systematic review of sedentary behaviour and health indicators in school-aged children and youth. Int J Behav Nutr Phys Act 8, 98.

17. Chinapaw MJ, Proper KI, Brug J et al. (2011) Relationship between young peoples' sedentary behaviour and biomedical health indicators: a systematic review of prospective studies. Obes Rev 12, e621-e632.

18. Fletcher E, Leech R, McNaughton SA et al. (2015) Is the relationship between sedentary behaviour and cardiometabolic health in adolescents independent of dietary intake? A systematic review. Obes Rev 16, 795-805.

19. Carsley S, Borkhoff CM, Maguire JL et al. (2015) Cohort profile: the Applied Research Group for Kids (TARGet Kids!). Int J Epidemiol 44, 776-788.

20. Statistics Canada (2011) Canadian Community Health Survey 2011. www.statcan.gc.ca/imdb-bmdi/instrument/3226_Q1_ V8-eng.pdf (accessed November 2020).

21. Anderson LN, Maguire JL, Lebovic G et al. (2017) Duration of fasting, serum lipids, and metabolic profile in early childhood. J Pediatr 180, 47-52 e 41.

22. Steiner MJ, Skinner AC \& Perrin EM (2011) Fasting might not be necessary before lipid screening: a nationally representative cross-sectional study. Pediatrics 128, 463-470.

23. de Onis M, Garza C \& Victora CG (2003) The WHO Multicentre Growth Reference Study: strategy for developing a new international growth reference. Forum Nutr 56, 238-240.

24. Dietitians of C, Canadian Paediatric S, College of Family Physicians of C et al. (2010) Promoting optimal monitoring of child growth in Canada: using the new WHO growth charts. Can J Diet Pract Res 71, e1-e3.

25. Carson V \& Janssen I (2012) The mediating effects of dietary habits on the relationship between television viewing and body mass index among youth. Pediatr Obes 7, 391-398.

26. Hajna S, Leblanc PJ, Faught BE et al. (2014) Associations between family eating behaviours and body composition measures in peri-adolescents: results from a communitybased study of school-aged children. Can J Public Health 105, e15-e21.

27. Larson NI, Miller JM, Watts AW et al. (2016) Adolescent snacking behaviors are associated with dietary intake and weight status. J Nutr 146, 1348-1355.

28. Lillico HG, Hammond D, Manske S et al. (2014) The prevalence of eating behaviors among Canadian youth using crosssectional school-based surveys. BMC Public Health 14, 323.

29. Lissner L, Lanfer A, Gwozdz W et al. (2012) Television habits in relation to overweight, diet and taste preferences in European children: the IDEFICS study. Eur J Epidemiol 27, 705-715.

30. Roos E, Pajunen T, Ray C et al. (2014) Does eating family meals and having the television on during dinner correlate with overweight? A sub-study of the PRO GREENS project, looking at children from nine European countries. Public Health Nutr 17, 2528-2536.

31. Zimmerman FJ \& Bell JF (2010) Associations of television content type and obesity in children. Am J Public Health 100, 334-340.

32. Gubbels JS, Kremers SP, Stafleu A et al. (2012) Clustering of energy balance-related behaviors in 5-year-old children: lifestyle patterns and their longitudinal association with weight status development in early childhood. Int J Behav Nutr Phys Act 9, 77.

33. Liang T, Kuhle S \& Veugelers PJ (2009) Nutrition and body weights of Canadian children watching television and eating while watching television. Public Health Nutr 12, 2457-2463.

34. MacFarlane A, Cleland V, Crawford D et al. (2009) Longitudinal examination of the family food environment and weight status among children. Int J Pediatr Obes 4, 343-352.

35. Vik FN, Bjornara HB, Overby NC et al. (2013) Associations between eating meals, watching TV while eating meals and weight status among children, ages 10-12 years in eight European countries: the ENERGY cross-sectional study. Int $J$ Behav Nutr Phys Act 10, 58.

36. Pirincci E, Durmus B, Gundogdu C et al. (2010) Prevalence and risk factors of overweight and obesity among urban 
school children in Elazig city, Eastern Turkey, 2007. Ann Hum Biol 37, 44-56.

37. Wansink B \& van Kleef E (2014) Dinner rituals that correlate with child and adult BMI. Obesity (Silver Spring) 22, E91-95.

38. Hardy LL, King L, Hector D et al. (2012) Weight status and weight-related behaviors of children commencing school. Prev Med 55, 433-437.

39. Brogan K, Danford C, Yeh Y et al. (2014) Cardiovascular disease risk factors are elevated in urban minority children enrolled in head start. Child Obes 10, 207-213.

40. Khoury M, Manlhiot C, Gibson D et al. (2016) Universal screening for cardiovascular disease risk factors in adolescents to identify high-risk families: a population-based cross-sectional study. BMC Pediatr 16, 11.

41. Ritchie SK, Murphy EC, Ice C et al. (2010) Universal versus targeted blood cholesterol screening among youth: the CARDIAC project. Pediatrics 126, 260-265.

42. Wong PD, Anderson LN, Dai DDW et al. (2018) The association of breastfeeding duration and early childhood cardiometabolic risk. J Pediatr 192, 80-85 e81.

43. Rey-Lopez JP, Ruiz JR, Vicente-Rodriguez G et al. (2012) Physical activity does not attenuate the obesity risk of TV viewing in youth. Pediatr Obes 7, 240-250.

44. Dallacker M, Hertwig R \& Mata J (2018) The frequency of family meals and nutritional health in children: a metaanalysis. Obes Rev 19, 638-653.

45. Birken CS, Maguire J, Mekky M et al. (2011) Parental factors associated with screen time in pre-school children in primary-care practice: a TARGet Kids! study. Public Health Nutr 14, 2134-2138.

46. Højsgaard S, Halekoh U \& Yan J (2006) The R package geepack for generalized estimating equations. J Stat Softw 15, $1-11$.

47. AAP Council on Communications and Media (2016) Media use in school-aged children and adolescents. Pediatrics 138, e20162592.

48. Ponti M \& Digital Health Task Force Digital Media (2019) Promoting Healthy Screen Use in School-Aged Children and Adolescents. https://www.cps.ca/en/documents/ position/digital-media (accessed July 2019).

49. van Buuren S \& Groothuis-Oudshoorn K (2011) mice: multivariate imputation by chained equations in R. J Stat Softw 45, 1-67.

50. World Health Organization. WHO Child Growth Standards R igrowup package; available from https://www.who.int/ childgrowth/software/readme_r.pdf (accessed October 2019).

51. R Core Team (2018) R: A Language and Environment for Statistical Computing. Vienna, Austria: R Foundation for Statistical Computing. https://www.R-project.org/ (accessed July 2018).

52. Canadian Paediatric Society DHTFOO (2017) Screen time and young children: promoting health and development in a digital world. Paediatr Child Health 22, 461-477.

53. Rao DP, Kropac E, Do MT et al. (2016) Childhood overweight and obesity trends in Canada. Health Promot Chronic Dis Prev Can 36, 194-198.

54. MacPherson M, de Groh M, Loukine L et al. (2016) Prevalence of metabolic syndrome and its risk factors in Canadian children and adolescents: Canadian Health Measures Survey Cycle 1 (2007-2009) and Cycle 2 (2009-2011). Health Promot Chronic Dis Prev Can 36, 32-40.
55. Wansink B (2004) Environmental factors that increase the food intake and consumption volume of unknowing consumers. Annu Rev Nutr 24, 455-479.

56. Powell LM, Szczypka G, Chaloupka FJ et al. (2007) Nutritional content of television food advertisements seen by children and adolescents in the United States. Pediatrics 120, 576-583.

57. Anderson GH, Hunschede S, Akilen R et al. (2016) Physiology of food intake control in children. Adv Nutr 7, 232S-240S.

58. Avery A, Anderson C \& McCullough F (2017) Associations between children's diet quality and watching television during meal or snack consumption: a systematic review. Matern Child Nutr 13, e12428.

59. Appannah G, Pot GK, Huang RC et al. (2015) Identification of a dietary pattern associated with greater cardiometabolic risk in adolescence. Nutr Metab Cardiovasc Dis 25, 643-650.

60. Ghobadi S \& Faghih S (2018) Eating breakfast and snacks while television viewing are associated with some cardio metabolic risk factors among Iranian children. Diabetes Metab Syndr 12, 235-243.

61. Monzani A, Ricotti R, Caputo M et al. (2019) A systematic review of the association of skipping breakfast with weight and cardiometabolic risk factors in children and adolescents. What should we better investigate in the future? Nutrients 11, 387 .

62. Shafiee G, Kelishadi R, Qorbani M et al. (2013) Association of breakfast intake with cardiometabolic risk factors. J Pediatr (Rio J) 89, 575-582.

63. Ho CY, Huang YC, Lo YT et al. (2015) Breakfast is associated with the metabolic syndrome and school performance among Taiwanese children. Res Dev Disabil 43-44, 179-188.

64. Reid Chassiakos YL, Radesky J, Christakis D et al. (2016) Children and adolescents and digital media. Pediatrics 138, e20162593.

65. Common Sense Media (2013) Zero to Eight: Children's Media Use in America 2013: A Common Sense Research Study. www. commonsensemedia.org/research/zero-to-eight-childrensmedia-use-in-america-2013 (accessed October 2019).

66. Marsh S, Ni Mhurchu C, Jiang Y et al. (2014) Comparative effects of TV watching, recreational computer use, and sedentary video game play on spontaneous energy intake in male children. A randomised crossover trial. Appetite 77, 13-18.

67. Lyons EJ, Tate DF \& Ward DS (2013) The better the story, the bigger the serving: narrative transportation increases snacking during screen time in a randomized trial. Int J Behav Nutr Phys Act 10, 60.

68. Lyons EJ, Tate DF, Ward DS et al. (2012) Energy intake and expenditure during sedentary screen time and motioncontrolled video gaming. Am J Clin Nutr 96, 234-239.

69. Blaine RE, Fisher JO, Blake CE et al. (2016) Conditioned to eat while watching television? Low-income caregivers' perspectives on the role of snacking and television viewing among pre-schoolers. Public Health Nutr 19, $1598-1605$.

70. Li S, Chen W, Srinivasan SR et al. (2003) Childhood cardiovascular risk factors and carotid vascular changes in adulthood: the Bogalusa Heart Study. JAMA 290, 2271-2276. 